\title{
The Use of Activity-Based Approach as Methodological Basis of Prospective Social Workers' Training to Sustainable Development of Social Groups in Ukraine
}

\author{
Natalia Kabus \\ Department of General Pedagogy and Pedagogy of Higher Education, \\ G.S. Skovoroda Kharkiv National Pedagogical University, Ukraine \\ e-mail: natali9901@mail.ru
}

\begin{abstract}
Keywords: sustainable development, sustainable development of social groups, activity, activitybased approach, action, subject and action approach, prospective social workers, training.
\end{abstract}

\begin{abstract}
The article shows the relevance of activity-based approach usage as methodological basis of prospective social workers' training to sustainable development of social groups. It is proved that future experts' training in this direction is important both for Ukraine and other countries. There have been revealed the types of activities (cognitive, creative, value-oriented, communicative), which provide the development of personality and social groups' subjectivity, their formation as the subjects of life and responsible social subjects that is essentail condition and indicator of their sustainable development. It has been emphasized that activity-based approach is the basis for the development of the technology of prospective social workers' training to sustainable development of social groups, which provides organization and management of this process as well as ensures gradual moving of prospective social workers to the level of self-management. There also has been substantiated necessity of the subjective and action approach usage (as important complement to activity one) which implementation ensures the development of subjective readiness of various social groups' representatives to individual and joint socially valuable actions that is essentail indicator of their sustainable development.
\end{abstract}

\section{Introduction}

As it is known, the implementation of the strategy of the civilization's sustainable development is one of the main issues of the XXI century. In the agenda XXI it is stated that its achievement is only possible by joint efforts of various social actors - both those who are the subjects of the implementation of state educational, social policy and social groups (children, youth, adults, family and community), who make up social structure of the society and determine vector of its development [1, p. 270-278]. However, representatives of these groups are not always characterized by harmony of their existence and are at the level of sustainable development. This determines the importance of organizing purposeful activity with a view to moving social groups up to the level of sustainable development. Sustainable development of social groups we consider as steady harmonious progress of social community on the basis of humanism, positive social interaction and solidarity, their output to the level of self-organization, when they are able to self care and mutual assistance, self-rehabilitation and self improvement, as well as to social creativity, consolidating efforts towards improving personal and social life. They are also characterized by awareness of social responsibility both for immediate and long-term results of their own activities.

We also would like to emphasize that solving the problem of social groups' sustainable development is important nowadays both for Ukraine and other countries, because no matter what level the society get, it always has elements that break its general harmony by practicing deviant, aggressive or self-destructive behavior, that have negative impact on its whole state. Moreover, important is the organization focused advancing social pedagogical activities for the prevention of personal and social deviations and stimulation various social groups' representatives to sustainable development on the basis of understanding social responsibility both for the results of their own life and individual contribution to the process of social change. In addition, scientists (M. Hvesyk, 
I. Koblyanska, L. Melnik, T. Nestorenko, A. Poccei, V. Shejko and others) confirm that disharmony of material and spiritual, creation and consumption, mind and spirit, personal and social are important causes of many global problems facing modern civilization $[2 ; 3, \mathrm{p} .9 ; 4 ; 5, \mathrm{p} .3]$.

This determines the critical importance of the implementation of social and educational activities which are aimed at harmonization of the development of individual (who is a representative of various social groups at the same time) in the unity of his thinking, feelings and will, value orientations, as well as raising the level of internal consolidation of various social groups, their ability to combine efforts for sustainable progressive development of society.

An important role in the implementation of these processes can have a social worker who interacts with the representatives of various social groups - both positive and 'risk groups' in his professional activity. It is the social worker, who in addition to providing social assistance also participates in the implementation of state social policy through realization socio-educational, preventive activities. According to this social worker (as well as a teacher and social pedagogue) has the possibility of positive social and educational impact on various social groups. In this regard, prospective social workers' training to the social and pedagogical activity for sustainable development of social groups is particularly relevant. We should note that the relevance of prospective social workers' training in this direction was grounded in details in the author's previous publications [6;7, p. 128]. We believe that such training should be based on activity-based approach, which is particularly important for solving the problem of sustainable development in general and sustainable development of social groups in particular, because, as practice shows, it is insufficient involvement of various social groups' representatives to socially valuable creative activity in the process of social education that explains its not high enough effectiveness.

Thus, the article is aimed to substantiate the importance, main directions and ways of activitybased approach implemention in the processes of prospective social workers' training to sustainable development of social groups.

\section{Research context and methodology}

The analysis of the scientific literature reveals that the implementation of the activity-based approach (B. Brushlinsky, E. Fallon, A. Leontiev, T. Prendergast, S. Rubinstein, S. Walsh and others) can be of great importance for solving the problem of prospective social workers' training to sustainable development of social groups. It is due to the presence of close relationship between categories 'activity' and 'development'. The study of interrelation between these concepts indicates that the holistic individual development is only possible due to the activities when he becomes the subject, but does not remain the object of external influence (in particular, social and educational one). It is the activity where axiological, cognitive and volitional spheres of personality, his qualities, creativity are being developed. Activity also provides gaining social experience and its further enrichment.

Researchers note that activity is purposeful conscious motivated form of active attitude to the world. In this regard, it is the basis, the means and the crucial factor for the development and selfdevelopment of its subjects [8-11]. At the same time the activity characterizes their ability to be the cause of changes in the being. It should be noted that the subjects of the activity can be individual, social group, society as a whole. The main function of the activity is ensuring the development of society and human civilization. Their development is associated with the improvement of activity methods, its differentiation and integration that promote the development of culture. An essential feature of the activity is the ability of its subjects to select the means of achieving desired results. And their ability to choose positive ways of activity instead of negative ones is particularly important. In addition, the activity as a conscious purposeful process is the managable one. In this regard promotion the subject's ability to self management and self-organization of his own activity as well as activization of the desire for self-development and self-improvement are of great importance in the context of their sustainable development.

The analysis of the activity characteristics let us assert that the implementation of the activitybased approach is crucial for solving the problem of sustainable development of social groups. As it 
was mentioned above, the main reason of low effectiveness of social assistance (in particular, towards people or families in difficult circumstances) is their insufficient involvement to the particular activity that would ensure their progressive development. As a result, person is often remains a passive consumer of social assistance that neither develop his will and personal qualities nor stimulate him to actions. The same concern to social and educational activity, preventive measures, as the person is not always promoted properly to socially valuable creative activity for improving social life. Often it is only an observer, user of external information, which is not transferred to the internal state during the activity [11, p. 238]. It does not provide integrity in education of any personal quality, because if individual does not participate in active work on promotion of positive values in the social environment, he will not become the subject of social and educational process. As we know, it is not quite enough to use verbal, informational methods of educational influence on human consciousness for his positive qualities formation and also his holistic harmonious development. What is more, even usage of dialogical methods (when person is engaged in the discussion, where he proves his point of view on certain problems, suggest ways of their solving) does not provide his full participation in the activities for improving social life.

We support the opinion of scientists (A. Guba, H. Popova and others), who note that the development of personality, who is ready to take responsibility for his actions and has an active social position, both understand the laws of effective life and use them in everyday life as well as tends to be creative is impossible without his involvement into activities. They confirm that only consolidation of knowledge and values in practical behavior and actions can provide achieving of positive results. Thus, only promotion of various social actors' activity, which provides gaining the experience of emotional and sensory perception and adoption of humanistic ideals and principles can form steady system of personal values [11, p. 229]. This is only possible if knowledge and values turn into individual beliefs through involvement of every person to socially valuable activities.

\section{Discussion and Results}

Thus, the implementation of activity-based approach is indispensable for future social teachers' training for sustainable development of social groups. This approach is applied at all levels of solving this problem. First of all, sustainable development of the individual as a representative of social group is only possible on condition of developing his subjectivity which is formed only during the activity. Subjectivity is the personal ability to be the subject of activities, life activity as well as the subject of self-development, who is able to plan, realize and correct it, overcome difficulties, meet the challenges to achieve the desired goal. A. Brushlinsky notes that it is necessary to become the subject of activities in order to be the author of his own history, his life. It should be added that we need to be the subject to become a creator of social life, who is capable to preserve, enrich and develop culture. Only being the subject person can consciously, creatively and responsibly determine the purpose of his life; find necessary means for its achieving as well as to move from concept to its implementation. Subject is able to show persistence, activity and creativity as well as overcom internal and external obstacles for achieving results. He also evaluates the results and integrates them into individual experience "becoming in such way all-sufficient author of his life" [8, p. 7]. Furthermore, when becoming the subject of his own development and life as well as responsible social subject, person gains the ability to make conscious choice in the system of social relations. He also can build his own strategy of life on the basis of moral principles of human existence through establishing positive relationships with other people, social and natural environment. Realizing clearly his own belonging to society and social mission subject can act consciously both for achieving his own and other people wellbeing, society and civilization prosperity, considering such activity as a valuable creative 'work-care', possibility for selfrealization his individuality.

Moreover, activity-based approach is also an important basis of social and educational activities for sustainable development of social groups. So, prospective social workers should be able to organize different activities on a high-level as well as to combine them into a holistic system 
in order to stimulate social groups to sustainable development. These activities are socioeducational, preventive, developing, creative, socio-cultural, recreational, correctional, rehabilitation, as well as activity to promote healthy lifestyles. We would like to emphasize necessity of involving representatives of various social groups in such activities as cognitive, creative, value-oriented and communicative, which are of great importance in the context of sustainable development. In this regard cognitive activity is focused on cognition basic laws and regularities of effective life and it promotes forming of world view on the basis of sustainability. Creative activity is aimed at 'constructive cultural transformation both person and the world for the benefit of all people'. Such activity ensures the development of subject's creative potential, his ability to find the best creative ways to solve life problems. As for value-oriented activity it is focused on promotion spiritual values in society and provides spiritual development of the subject, forming his ability to perceive the world and its objects as values. Communicative activity ensures the development of social qualities as well as creating of humanistic interpersonal relations on the basis of human values.

It should be noted that social groups' stimulating to sustainable development that is holistic, harmonious one, suggests their involvement in all the activities mentioned above, which are closely interrelated. Taking into account that that axiosphere is the unifying core of the individual integrity, we believe that value-oriented activity is systemically important one that promotes formation of the subject's valuable orientations. These orientations are realized in the individual activities, actions, relationships with other people and the world around and determine positive direction of the subject's cognitive, creative and communicative activities, social interaction as a whole.

It should be stressed that in the context of sustainable development of social groups crucial is social worker's ability to promote their representatives both to the activity for their own selfdevelopment and to joint socially valuable activities (in particular public, volunteering, social creativity with a view to promote positive values, improve social life). Such activities provide interaction between subjects, which suggests cooperative determining of purposes and objectives, principles, content, methods and forms of activity, its joint implementation and discussion of the results. It should be emphasized that conscious and voluntary participation of different social groups' representatives in such activities is only possible due to actual awareness of its importance and value to the subjects. In this regard we should find something common that unites people and encourage their actions both for personal self-development and improving the world. It is no doubt that active participation in these activities provides both holistic development of axiological, cognitive, volitional spheres of individual and personality and social groups' forming as the subjects of life and social subjects who are able to individual and joint activities, uniting efforts for sustainable development of society.

Speaking about social and pedagogical activity for sustainable development of social groups we should take into account that the effectiveness of the activity in certain direction is provided by establishing the processes of organization, management and communication [12, p. 33-34]. In accordance with mentioned above, social worker's activity vith a view to promote sustainable development of social groups suggests implementation of actions of all three kinds. Firstly, social worker should be able to organize the process under investigation through selection of relevant content, methods, forms, techniques of social and pedagogical activities which would provide holistic effect on axiological, cognitive, volitional spheres of personality as well as axiological, world view and activity focus of social groups and at the same time would contribute to harmonization of their personal and social development through value awareness of joint activities, social cohesion and consolidation. Secondly, social worker should be able to manage this process with gradual formation of social groups' ability to self-management. It is possible due to organizing joint activities of various social groups for mutual assistance in solving their own problems. Moreover, the level of self-management is characterized by capacity of various social actors such as children, youth, adults, seniors, family and community to consolidate efforts for solving important social problems. Thirdly, it suggests establishing communication, dialogical social interaction between members of different social groups. Such interaction provides a process of interiorization 
and exteriorization of knowledge, values, experiences and activity results as well as mutual enrichment of its subject. It also promotes awareness the importance both self-development and joint activities for improving social life, strengthening motivation for further action.

In addition, the activity-based approach is also an important basis for prospective social workers' training to sustainable development of social groups. This training is realized through all kinds of activities in higher education - educational, volunteering, research and socio-pedagogical practice. In its turn, they encourage students to active cognitive, creative, value-oriented and communicative activity, providing holistic effect on future social workers - from awareness of the importance of activity in direction under the study to gaining the experience in this field.

Thus, it is the activity-based approach that is used for developing the technology of prospective social workers' training to sustainable development of social groups. This technology includes three stages such as motivational and orientational, developmental and activity, reflexive and creative. The backbone factors of these stages are organization, management and communication.

So, first, motivational and orientational stage is aimed both at awareness of future social workers the importance of implementation the strategy of sustainable development of civilization and understanding of their role as well as the role of the individual and social groups in its achieving. During the study such subjects as "Introduction to the specialty", "Social pedagogy", "Social Work", "Fundamentals of professional creativity in the social sphere", "Fundamentals of socialization", "Work with various social groups" and others students acquire knowledge of the essence and characteristics of sustainable development, the specifics of different social groups and ways of working with them.

During the second developmental and activity stage prospective social workers in addition to studying professionally oriented subjects are involved in active social and educational practice, which usually takes place in schools, boarding schools, centers of social services for families, children and youth, rehabilitation centers. They also take an active part in volunteering by interacting on a voluntary basis with children, youth and families in kindergartens, schools, orphanages, rehabilitation centers, public organization, clubs for people with disabilities and their families where they organize socio-educational, joint creative activity, preventive and other work, oriented at promoting their sustainable development. We would like to note that volunteering experience of students future social pedagogues of G.S. Skovoroda Kharkiv National Pedagogical University is presented in detail in the relevant article of the author [13, 14]. All this provides improvement of constructive, projective, communicative, organizational, managerial, research, creative and other students' skills as well as their mastering the system of methods, techniques and technologies to promote social groups to sustainable development. Moreover, the stage provides initial gaining the experience of professional work in various social spheres, which intensifies thinking, feelings and will of the students. This promotes understanding of the creative nature of professional work, social responsibility for its results and encourages prospective social workers to further self-development.

The reflexive and creative stage is characterized by active creative research work of students that is oriented on developing and implementation their own programs and projects, creation of social advertising with a view to stimulate representatives of various social groups to sustainable progressive development as well as by searching of innovative forms and methods of the activities in this area. This stage reflects the level of students' self-management by their own work.

The implementation of this technology ensures gaining the experience by prospective social workers in the direction under study as well as their development as the subjects of activity for sustainable development of social groups. Moreover, it promotes the development of future social workers' personality, particularly their spiritual, moral and professional qualities, creative potential, reaching the level of sustainable development and self-development.

Thus, the activity-based approach is one of the basic in the context of prospective social workers' training for solving the problem of our research. It provides both the development of social workers and gaining the ability to design and implement the system of social and pedagogical 
activity to encourage social groups to sustainable development. This suggests the involvement of their representatives into activities for their own improvement as well as joint actions to improve social life. As it was also mentioned above, social and pedagogical activity is aimed at the development of subjectivity of different social groups' representatives, their gradual moving up to the level of self-development and self-organization, when they both act consciously to improve their own and social life and also encourage other people to such activities.

At the same time, despite the positive characteristics of the activity approach, we would like to draw attention to such contradiction. During the life person is usually involved in various activities: educational, labor, communicative, socio-cultural, professional and other ones, but he does not not always become a real subject of life activity, who is able to be responsible creator of his own life and in particular the subject of moral actions. Consciously person usually realizes how to act, but on a subconscious level he can act spontaneously, not always showing himself through positive actions. So, something is lost during activity.

In our opinion, there are several reasons for this situation. Firstly, person can participate in various activities on in a formal way, not always understanding properly their significance and value. As a result, individual does not reach creative level of activity that provides the development of subjective qualities. Secondly, it is not everyone who fully aware of the responsibility for his actions as well as the importance of humanistic orientation of any activity. Thus, there is a loss of spiritual and moral superstructure of the activity that does not provide a synergetic effect. The critical state of modern civilization proves that activity not always provides holistic development of the person, who has a high level of spirituality. Therefore, synergetic (mutual strengthening) orientation of various activities on achieving positive harmonized results is of great importance nowadays. Moreover, despite an adequate level of education, people do not always show themselves through specific actions and become the subjects of moral act. Scientists note that triumph of the individuality, which is not supported by higher level of sociality that are characterized for modern civilization as well as most people's focusing on their own interests cause some indifference both to other people's life and the state of society and the environment. As a result, this leads to a loss of person's ability to actions. So, participation in the activity does not always provide the development of personal ability to socially valuable actions What is more, it is proved by scientists that activity is a conscious purposeful process, person participates in it if he has certain motives. However, the ability to positive actions should be formed on subconscious level, when person automatically shows himself through moral behavior $[15,16]$.

In this regard we support the view of scientists (I. Prokopenko, V. Tatenko, V. Shulga and others) who emphasize necessity of improving, specifying methodological approaches that correspond to the requirements and challenges of our time $[15$, p. $3 ; 17$, p. 54]. We believe that society's achievement of the level of sustainable development requires individual and social groups' forming as the subjects who are capable of specific individual and joint positive actions. It can be achieved on the basis of subject and action approach which is a specification of the activity one and provides the implementation of socio-educational technologies that promote activisation of personality and social groups' spiritual resources as well as their subjective activity potential. Such approach provides forming of social subjects' ability to the moral and creative actions, which are deeds aimed at promoting spiritual values and improving human relations. Scientists (V. Tatenko, $\mathrm{V}$. Shulga) also point that action is important condition and mechanism of the subject's selfrealization [15-16].

It should be noted that the essence of subject and action approach (that is substantiated by Ukrainian psychologist V. Tatenko) is the integration of two ideas [15, p. 3-13]. The first one is the concept of man as the subject of life and mental activity, who is capable of responsible purposeful impact on himself and others (A. Brushlinsky) [8]. The second one is the idea of the action as the highest form of spiritual socially valuable activity (V. Tatenko) [15, p.4]. The researchers emphasize that psychological readiness for the activity reveals itself on the conscious level. At the same time, the subjective readiness to action shows itself both at conscious and unconscious levels, so action can be either purposeful or spontaneous activity [16, p. 100]. 
Moreover, scientists note that the subjective readiness of individual and social groups to positive actions can not be developed through such mechanisms as exercises, obligations, sanctions. It can be developed only at the inner spiritual level of social subject on the basis of steady value orientations. Researchers emphasize that formation of subjective readiness to action is possible by means of joint action of various social actors such as social workers, teachers, parents, representatives of volunteer and public organizations, as well as those who are encouraged to act $[15,16]$. They say that "joint action is a special form of human interaction that provides cooperative creation of unique individually and socially meaningful values by people and is realized for the purpose of constructive and productive solving of contradictions of individual and social life by participants of social interaction" [16, p. 101]. It should be noted that joint action as well as the examples of individual and collective actions of other people provide a holistic impact on subject's axiological, mental and volitional spheres. All this provides such interaction of internal and external forces, which ensure subject's achievement the level of spiritual development.

Thus, the subject and action approach is an important complement to activity one as well as important theoretical and methodological basis both for individual and social groups' development. It is also an important basis for prospective social workers' training to sustainable development of social groups. Students should be aware of the importance of forming subjective readiness to individual and joint moral and creative actions and consider such readiness as essential condition of subject's sustainable development. Future specialists should also be able to form such readiness by means of social pedagogical activity.

Finally, we would like to note that the training of prospective social workers to sustainable development of social groups at the Faculty of Psychology and Sociology at G.S. Skovoroda Kharkiv National Pedagogical University on the basis of activity-oriented approach has proved its effectiveness. The observation of students has shown that most of them are at the level of sustainable development - they aspire to personal, professional and creative self-improvement for the implementation their professional activity at the creative level. They also work actively to stimulate various social groups' representatives both to their own self-development and joint activity for improving social life.

\section{Conclusions}

Thus, the study allows asserting that the implementation of the activity-based approach is crucial both for solving the problem of sustainable development of social groups and training of prospective social workers in this direction. It has been shown that future experts' training in this direction is important nowadays both for Ukraine and other countries, because no matter what level the society get, it always has elements that break its general harmony. It has been shown that participation in the activitiy is crucial condition of personality and social groups' sustainable development. It has been substantiated that cognitive, creative, value-oriented and communicative activities are the most important in the context of sustainable development as these kinds of activities properly provide holistic development of individuial (who at the same time is a representative of various social groups) as well as promote developing his subjectivity.

It has been proved that there are two main directions of social pedagogical activities with a view to sustainable development of social groups. The first one is aimed at the holistic development of axiological, cognitive and volitional spheres of representatives of different social groups as well as their development as the subjects of life and their own development who are able to prevent and solve life problems. The second one is focused on harmonization personal and social development, their becoming as responsible social subjects, representatives of family, community, nation, civilization, who are ready to consolidate efforts for sustainable progressive development of society.

Moreover, the activity-based approach is the basis for the development of the technology of prospective social workers' training to sustainable development of social groups, which provides organization and management this process as well as ensures gradual moving of prospective social workers to the level of self-management. There also has been substantiated necessity of the subjective and action approach usage (as important complement to activity one) which 
implementation ensures the development of subjective readiness of various social groups' representatives to individual and joint socially valuable actions that is essentail condition and indicator of their sustainable development.

\section{References}

[1] Information on: http://sustainabledevelopment.un.org/ content/documents/Agenda21.pdf.

[2] M.A. Hvesyk, I.K. Bystryakov, L.V. Levkovskaya, Sustainable development: worldview ideology of future, Institute of Environmental Economics and Sustainable Development, Kyiv, Ukraine, 2012.

[3] L.G. Melnik, I.I. Koblyanska, T.V. Nestorenko, Sustainable development: theory, methodology, practice, University book, Sumy, Ukraine, 2009.

[4] A. Poccei, The human quality, Pergamon Press, Oxford, 1977.

[5] V.N. Shejko, Culture. Civilization. Globalization (late XIX - early XXI century), Basis, Kharkiv, Ukraine, 2001.

[6] N.D. Kabus, Relevance of future social workers training to sustainable development of social groups, Pedagogy and Psychology of the creative person formation at high and higher schools. 42 (2015) 144-151.

[7] N.D. Kabus, The role of social groups in implementation of the strategy of the society sustainable development, Scientific works: Scientific-methodical journal. 234 (2014) 124129.

[8] A.V. Brushlinsky, Sociality of the subject and the subject of sociality, in: A.V. Bruschlinsky, Subject and person's social competence, Institute of Psychology RAS, Moscow, 1995, pp. 323.

[9] E. Fallon, S. Walsh, T. Prendergast, An activity-based approach to the learning and teaching of research methods: measuring student engagement and learning, Irish Journal of Academic Practice. 1 (2013) 1-25.

[10] A.N. Leontiev, Activity. Consciousness. Personality, Sense, Moscow, Russia, 2004.

[11] H.V. Popova, A.V. Guba, Activity-based approach, in: V.I. Lozova (Ed.), Scientific approaches to educational researches, Apostrophe, Kharkiv, Ukraine, 2012, pp. 216-244.

[12] T. Dmitrenko, T. Lavryk, E. Yaresko, Pedagogical conditions as a subject for scientific research in Ukraine: nature, structure, characteristics, and functions, International Letters of Social and Humanistic Sciences. 69 (2016) 32-38.

[13] N.D. Kabus, Summarizing the experience of students' future social pedagogues volunteering in the context of sustainable development and health preservation of personality, American Journal of Nursing Research. 3 (2015) 8-13.

[14] N.D. Kabus, Professional and creative development of future social worker in the learning process in higher school, in: T. A. Dmitrenko (Ed.), Development of creative potential of the future specialist, Vishemirovsky, Kherson, Ukraine, 2014, pp. 334-373.

[15] V.A. Tatenko, Subjective-actional paradigm in modern psychology, Social Psychology. 1 (2006) 3-13.

[16] V.D. Shulha, Subjective-actional approach for the development of the essential powers of a child: methodology of pedagogy of the XXI century, Science and Education a New Dimension. Pedagogy and Psychology. 27 (2014) 99-102.

[17] I. Prokopenko, Development of innovative pedagogical education as the priority direction of modernization of national systems of educational staff training in the XXI century, The theory and practice of social systems' management. 1 (2013) 48-55. 